\section{Academic promotion in Italy}

SIR - As the actual winners pilloried in the letter on "Academic promotion in Italy" (Nature 353, 10; 1991), we should like to reply to the comment and assessments made therein by the author, who was one of the losers in the competition in question. His graph showed that his four selected losers had bibliometric evaluations more weighty than ours. Because of the well-recognized 'impact factor' of Nature, this article has been reported by several leading Italian newspapers with vignettes of a typical professor endowed with donkey's ears.

Bibliometrics may be widely used in the evaluation of research performance but, like statistics, it is nonetheless best left to experts. Thus a bibliometric analysis carried out over a long period of time will chiefly reflect past performance, instead of present scientific activity. Moreover, for academic promotion in a specific area, the appropriate number of candidate's citations must be that in this particular area, and not the whole field of medical science. These simple criteria were not respected in the analysis presented by the loser: a period of 23 years was evaluated, with no attempt to confine the citations to a specific field. Such an approach could, for example, enable an ophthalmologist on the verge of retirement to win a chair of urology.

We, nonexperts like the loser, have undertaken our own examination of the

\section{Is anybody there?}

SIR - In his favourable review of my book The Cosmic Water Hole (Nature 354, 334; 1991), Frank J. Tipler misrepresents my position on the issue of extraterrestrial intelligence. He states that "he [the author] admits that the search will probably fail because such intelligence probably does not exist". This does not correspond to anything I said in the book. I seriously consider the possibility that we are alone, but nowhere do I admit that the search will probably fail, and/or that extraterrestrial intelligence probably does not exist. In fact, the book was an attempt to convince people that these searches can benefit mankind, regardless of their outcome. Because the searches rest on an untested assumption, they have been (and still are) difficult to fund. While I don't contest Tipler's right to criticize the SETI projects, I do not want to share the responsibility of condemning and thus compromising them.

Observatoire Midi-Pyrénées,

EMMANUEL DAVOUST

14 Avenue Edouard-Belin,

31400 Toulouse, France bibliographic material. We carried out a very simple count of the number of citations provided by the Science Citation Index during the past seven years (1984 90) for the five winners and the loser in question. Interestingly, four of the winners had at least twice as many citations as the loser, whereas the fifth had a comparable number (see figure). It is

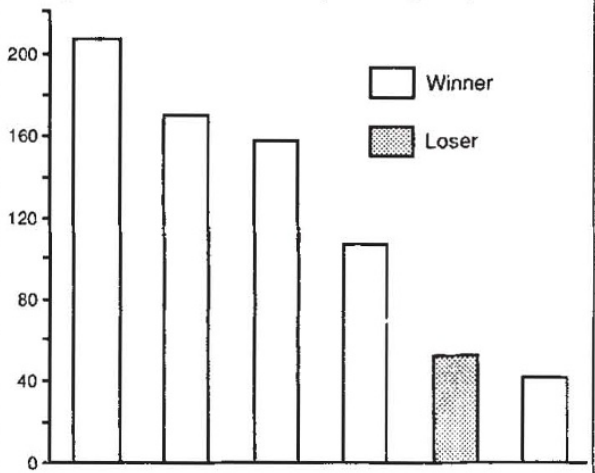

curious that these results are diametrically opposite to those found by the loser. This is just further proof that bibliometrics is a complex matter. This is not to deny the need for improvements in the complex machinery for academic promotion in Italy. But the thinly veiled complaints of a loser cannot but cast aspersions on the reputation of all holders of academic posts.

SERGIO AMADOR

CARLO BERNASCON

MARIO BOCCADORO

ROSARIO GIUSTOLIS

MARCO GoBB

Dipartimento di Medicina

ed Oncologia Sperimentale,

Universita di Torino,

Via Genova 3, 10126 Torino, Italy

\section{Sequence data}

SIR - I read with interest your leading article "Free trade in human sequence data" (Nature 354, 171; 1991).

There are two main reasons why a biotechnology or pharmaceutical company might be interested in obtaining cDNAs and their sequences and there are several ways of getting them quite independent of any large-scale human genome sequencing initiative.

It is important to distinguish between cDNA sequences that code for proteins with potential therapeutic use and those that code for proteins, modulation of the activity of which might be used therapeutically. A useful paradigm for the former is the colony stimulating factors and of the latter the seven transmembrane receptor proteins and the ion channels. The cloning and sequencing of the cDNAs for many of these proteins have appeared in Nature. Generally, this has been done either by cloning for protein function or from amino acid sequence via oligonucleotides.

There are interests in comparing cDNAs from diseased and normal tissue but it should be realized that these fishing expeditions are usually unhelpful and sometimes misleading. A case in point would be the disease of cystic fibrosis, the genetic lesion for which was uncovered by linkage analysis and not by examination of 'diseased' tissue. In my view, it is unlikely that companies will undertake large-scale tissue-specific cDNA sequencing projects, largely because it is virtually impossible to know which difference to chase if and when you find it. Thus the preferred route to cDNA collection is a deterministic one. They are obtained for a particular reason: either to test expressed protein for potential therapeutic use or to be used to set up assays to look (for example) for receptor selective compounds.

How, therefore, might a random collection of cDNA sequences be of use to the drug hunters? It is possible that distant relatives of proteins with proven therapeutic utility could be uncovered. This is likely to be thrown up by sophisticated computer-driven sequence manipulation and comparison at the nucleic acid and protein level. cDNAs coding for such proteins are potentially valuable (analogous to a compound related to another compound with proven therapeutic use) but there is a long way to travel before that potential value is realized. The protein has to be expressed and characterized and its in vivo activity assessed well before therapeutic assessment in humans. Very much a case of a protein looking for a disease to cure.

It is equally likely that novel members of existing receptor super-families will be revealed by the same techniques, for example orphan receptors of the steroid receptor family, novel seven ${ }^{1 \cdot}$ transmembrane receptors with unknown ligands and novel 'adhesion' molecules. Once again, considerable work has to be done to uncover what the role of these proteins might be - work that would usually precede any large-scale effort to find small molecules that might affect them. Indeed, several orphan receptors exist already and there is now a hunt for the ligands. So it is the analysis of cDNA sequences that will reveal potential utility: much work will remain to prove it.

It is not sensible for me to debate the issue of patenting such DNA sequences, because it is essentially a legal question. Nevertheless, it is useful to remember what the actual value of cDNA sequences might be 'commercially' and what it will take to realize it.

Glaxo Group Research Limited,

T. J. R. HARRIS

Greenford, Middlesex UB6 OHE, UK 